Article

\title{
Inorganic Phosphate in the Pathogenesis of Pregnancy-Related Complications
}

\author{
Ana Correia-Branco ${ }^{1}$, Monica P. Rincon ${ }^{2}{ }^{-}$, Leonardo M. Pereira ${ }^{2}$ and Mary C. Wallingford ${ }^{1, *}$ \\ 1 Mother Infant Research Institute, Tufts Medical Center, 800 Washington Street, Boston, MA 02111, USA; \\ ana.clmc.branco@gmail.com \\ 2 Maternal Fetal Medicine, Oregon Health Science Center, Mailcode L-458, 3181 SW Sam Jackson Park Road, \\ Portland, OR 97219, USA; rincon@ohsu.edu (M.P.R.); pereiral@ohsu.edu (L.M.P.) \\ * Correspondence: mwallingford@tuftsmedicalcenter.org; Tel.: +1-617-636-5982; Fax: +1-617-636-1469
}

Received: 9 June 2020; Accepted: 23 July 2020; Published: 25 July 2020

\begin{abstract}
Inorganic phosphate $\left(\mathrm{P}_{\mathrm{i}}\right)$ is an essential nutrient that fulfills critical roles in human health. It enables skeletal ossification, supports cellular structure and organelle function, and serves key biochemical roles in energetics and molecular signaling. $P_{i}$ homeostasis is modulated through diet, intestinal uptake, renal reabsorption, and mobilization of stores in bone and extracellular compartments. Disrupted $P_{\mathrm{i}}$ homeostasis is associated with phosphate wasting, mineral and bone disorders, and vascular calcification. Mechanisms of Pi homeostasis in pregnancy remain incompletely understood. The study presented herein examined biological fluid Pi characteristics over the course of gestation. Correlations with gestation age, pregnancy number, preterm birth, preeclampsia, diabetes mellitus, and placental calcification were evaluated during the last trimester. The results support that maternal urinary $P_{i}$ levels increased during the third trimester of pregnancy. Reduced levels were observed with previous pregnancy. Amniotic fluid $P_{i}$ levels decreased with gestation while low second trimester levels associated with preterm birth. No significant difference in urinary $P_{\mathrm{i}}$ levels was observed between preeclampsia and controls $(8.50 \pm 2.74$ vs. $11.52 \pm 2.90 \mathrm{mmol} / \mathrm{L})$. Moreover, increased maternal urinary $P_{i}$ was associated with preexisting diabetes mellitus in preeclampsia. Potential confounding factors in this study are maternal age at delivery and body mass index (BMI) - information which we do not have access to for this cohort. In conclusion, $\mathrm{P}_{\mathrm{i}}$ levels provide clinical information regarding the pathogenesis of pregnancy-related complications, supporting that phosphate should be examined more closely and in larger populations.
\end{abstract}

Keywords: inorganic phosphate; preeclampsia; diabetes mellitus; pregnancy; placental calcification

\section{Introduction}

Phosphorus is an essential micronutrient that serves as key biochemical roles in cellular structure, organelle function, energetics and molecular signaling, and skeletal ossification. Phosphorus is a primary component of hydroxyapatite crystals, which are minerals that reinforce bone strength $[1,2]$. Elemental phosphorus circulates in the blood in the form of phosphoric acid $\left(\mathrm{PO}_{4}\right)$, also termed inorganic phosphate or phosphate $\left(\mathrm{P}_{\mathrm{i}}\right) . \mathrm{P}_{\mathrm{i}}$ homeostasis is modulated through diet, intestinal uptake, renal reabsorption, and mobilization of stores in bone and extracellular compartments. Disrupted $P_{i}$ homeostasis is associated with $P_{i}$ wasting, refeeding syndrome, chronic kidney disease (CKD) mineral and bone mineralization disorders (BMD), and medial vascular calcification. $P_{i}$ transport into cells (symport) occurs against a 100-fold concentration gradient via transmembrane phosphate transporter proteins, such as the type III sodium-dependent phosphate transporters Slc20a1 (PiT-1) and Slc20a2 (PiT-2). In early preeclampsia (PE), placental expression of the sodium-dependent phosphate transporters Slc20a1 and Slc20a2 is highly reduced; yet in late PE, Slc20a2 is significantly 
increased [3]. The cause for these alterations remains unknown. In the nongravid state, $\mathrm{P}_{\mathrm{i}}$ homeostasis is regulated through multi-system endocrine signaling in conjunction with calcium via systemic activity of phosphatonins including parathyroid hormone (PTH), vitamin D (VD), and fibroblast growth factor 23 (FGF23). The parathyroid gland responds to decreased calcium levels and regulates PTH secretion which increases blood calcium levels by stimulating release of calcium and $P_{i}$ from bone, as well as altering calcium reabsorption, $\mathrm{P}_{\mathrm{i}}$ excretion, and VD production by the kidney, which in turn increases intestinal reabsorption [4-8]. FGF23 signaling downregulates $P_{i}$ transporter gene expression and inhibits production of VD and PTH $[4,5]$. During fetal development, placental mineral transport and micronutrient accretion is regulated in part by $\mathrm{PTH}$-related protein $(\mathrm{PTHrP})$ and possibly $\mathrm{PTH}$, but not by calcitriol, FGF23, calcitonin, or the sex steroids [5]. In the fetus, fetal kidneys and fetal membranes contribute to production and regulation of amniotic fluid and $P_{i}$ can undergo several routes [5,9]. At least five pathways of exchange have been identified between the amniotic space and the surrounding tissues, indicating multiple routes by which $P_{i}$ can be exchanged between amniotic fluid and the developing fetus, where the large majority of $P_{i}$ undergoes accretion and plays a crucial role in skeletal ossification during the latter half of pregnancy [9]. In nonpathological conditions, fetal serum $P_{\mathrm{i}}$ levels are maintained approximately $0.5 \mathrm{mmol} / \mathrm{L}$ higher than in the mother [5].

$\mathrm{PE}$ is a complex and pregnancy-specific hypertensive syndrome. It is reported that women who have developed PE in pregnancy are at increased risk of cardiovascular disease, coronary artery calcification, stroke, and chronic kidney disease later life [10-14]. PE is characterized by hypertension and proteinuria after 20 weeks' gestation, and is frequently associated with placental dysfunction, although the etiology remains unknown at the molecular level $[15,16]$. PE affects 3-5\% of pregnancies worldwide and is one of the leading causes of maternal and fetal morbidity and mortality [16-18]. The standard features of PE are new-onset hypertension (defined as a systolic blood pressure of $140 \mathrm{~mm} \mathrm{Hg}$ or more, or a diastolic blood pressure of $90 \mathrm{~mm} \mathrm{Hg}$ or more on two occasions at least $4 \mathrm{~h}$ apart after 20 weeks of gestation; or systolic blood pressure of $160 \mathrm{~mm} \mathrm{Hg}$ or more, or a diastolic blood pressure of $110 \mathrm{~mm} \mathrm{Hg}$ or more on two occasions at least $4 \mathrm{~h}$ apart after 20 weeks of gestation) and proteinuria (300 $\mathrm{mg}$ or higher in a $24 \mathrm{~h}$ urine specimen) [16]. Pregnancy adaptations change maternal bone metabolism, resulting in an uncoupling of mineral resorption and deposition rates to a state of high bone turnover to support the skeletal bone growth requirements of the fetus [19]. Studies show that bone turnover biochemical markers increase in pregnancies complicated by preeclampsia [20]. Interestingly enough, although maternal bone mineral density (BMD) is unaffected by preeclampsia [21,22], adult offspring who were previously exposed to maternal preeclampsia in the womb present higher BMD levels than those not exposed [23,24].

High levels of dietary Pi consumption and high circulating levels of Pi induce ectopic medial vascular calcification, the deposition of calcium-phosphate mineral in the smooth muscle cell layer of blood vessels. Vascular calcification requires phosphate for the chemical foundation of the calcium-phosphate mineral, in the form of hydroxyapatite, and high Pi levels induce pathological expression of osteochondrogenic proteins by smooth muscle cells [25-27]. High extracellular phosphate has been described to impose a significant cardiovascular risk through promoting vascular calcification, an independent risk factor for cardiovascular morbidity [26]. Ectopic calcification can occur in the placenta tissue and is frequently observed in pregnancy. However, clinical research on the association between placental calcification and clinical outcomes and acute disease such as PE is limited, the etiology of placental calcification remains undefined, and the clinical significance of placental calcification remains unclear $[18,28-30]$. Therefore, the aim of this research was to examine biological fluid (maternal urine, amniotic fluid) $P_{i}$ characteristics over the course of gestation and to evaluate correlation with gestational age at delivery, pregnancy number, preterm birth, preeclampsia, diabetes mellitus, and placental calcification. 


\section{Materials and Methods}

\subsection{Nonhuman Subjects Research}

Ethical review for the enclosed de-identified amniotic fluid, urine, and placenta analyses were performed by the University of Washington Human Subjects Division. Subcommittee E/B determined that this activity does not meet the federal regulatory definition of "human subjects" research under 45 CFR 46.102. Application numbers are as follows: Non-Identifiable HSD \#47984 (placenta and urine specimens) and HSD \#51806 (amniotic fluid specimens).

\subsection{GAPPS Cohort Samples}

Maternal urine and placental tissue section samples from 9 normotensive pregnant women and 7 preeclamptic women were purchased from the Global Alliance for the Prevention of Prematurity and Stillbirth (GAPPS). Preeclampsia was defined by standard clinical criteria [16]. Gestational ages were between 28.7 and 33 weeks. Samples were coded by GAPPS without any patient identifiers and analyzed without knowledge of the disease status. Specimens from participants with a history of smoking were excluded from this study. Participants were characterized with preexisting pregnancies and divided in two groups as follows: first pregnancy and second pregnancy. Participants were characterized with preexisting diabetes mellitus, which included Type I, Type II and Gestational Diabetes Mellitus, and divided in two groups as follows: normal glucose tolerance (NGT) and diabetes mellitus. Maternal urine and amniotic fluid aliquots were stored at $-80{ }^{\circ} \mathrm{C}$ until analysis.

\subsection{OHSU Amniotic Fluid Samples}

De-identified amniotic fluid samples were obtained from OHSU (MTA-OUT16-095). A total of $11 \mathrm{~s}$ trimester and 9 third trimester samples were obtained. Gestation age of delivery (GAD) ranged between 25 and 39 weeks on average. Gestation age of sample collection (GASC) ranged between 17 and 35 weeks on average. We tested whether amniotic fluid phosphate levels were an indicator for preterm or early pre-term birth for second and third trimester of pregnancy.

\section{4. $P_{i}$ Quantification}

Maternal urine $P_{\mathrm{i}}$ levels were determined with the Phosphate Assay Kit (Sigma Aldrich, St. Louis, MO, USA; MAK308) and amniotic fluid $P_{i}$ levels were determined with the QuantiChrom Phosphate Assay Kit (Bioassays Systems, Hayward, CA, USA; DIPI500) according to the manufacturer's instructions.

\subsection{Methods for Von Kossa Staining and Imaging of Placenta Tissue}

The von Kossa staining was performed as previously described in Speer et al. 2009 [31] with the inclusion of an optimally reduced 22 min von Kossa treatment. Placental tissue section from 8 normotensive pregnant women and 8 preeclamptic women were stained, and images of mounted sections were acquired on a Keyence BZ-X800 microscope using the Keyence BZ-X software (Keyence, Ozaka, Japan) at $4 \times$ magnification. File names were coded. Individual calcified lesions were imaged on a Nikon E800 Upright Microscope (Nikon Corp., Tokyo, Japan) at 2.5 and 10× magnification and file names were coded. Semi-quantitative analysis of calcified lesions was performed on all tissue sections using ImageJ/Fiji (NIH, Bethesda, MD, USA) histomorphometry software.

\subsection{Statistical Analysis of Experimental Data}

The following statistical tests were used to analyze quantitative data in GraphPad Prism 6 software for Windows (GraphPad Software Inc., La Jolla, CA, USA). For comparison of two groups, a $p$-value was determined by a two-tailed Student's T-test with unequal variance. For comparison of three or more groups, a $p$-value was determined by a Welch's T-test with unequal variance. Slope calculations were obtained by Deming (model II) linear regression. 


\section{Results}

\subsection{Clinical Characteristics}

Participant characteristics are shown in Figure 1. The gestational ages at delivery (GAD) is statistically significantly higher in the preeclampsia group compared to the normotensive group (32.08 \pm 0.27 and $30.68 \pm 0.49$ weeks; $p=0.0375$; Figure $1 \mathrm{~A})$. A statistically significant association was not observed between preexisting pregnancies and normotensive or preeclampsia groups $(0.56 \pm 0.18$ and $0.43 \pm 0.20 ; p=0.6420$; Figure $1 \mathrm{~B})$, or preexisting diabetes mellitus $(100 \% \pm 40 \%$ and $129 \% \pm 45 \%$; $p=0.6420$; Figure 1C).

A.

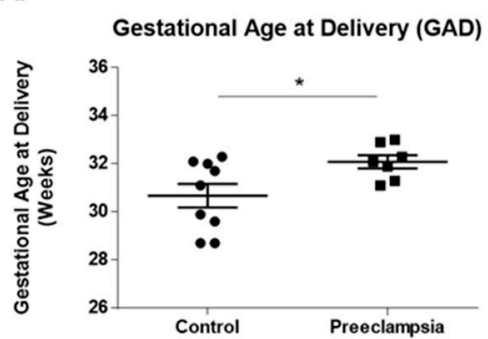

B.

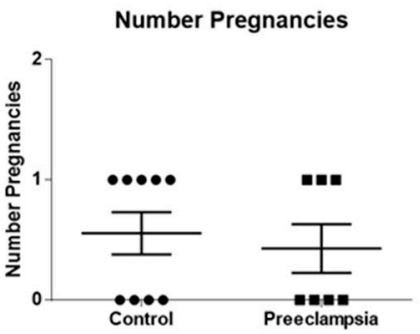

c.

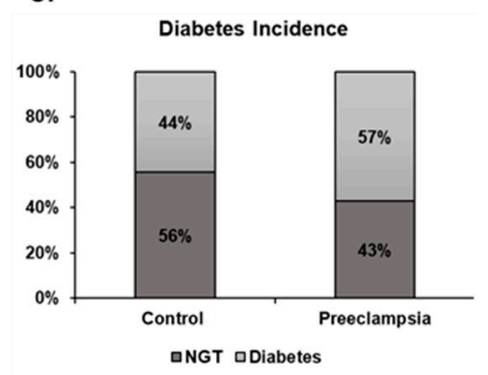

Figure 1. Clinical characteristics of cohort and association with preeclampsia. Clinical characteristics of cohort (control, $n=9$; preeclampsia, $n=7$ ). We observed that gestational age at delivery (GAD) was increased in the Preeclampsia group (A). We did not observe differences on the preexistence of pregnancies $(\mathbf{B})$ and diabetes incidence $(\mathbf{C})$ in both Control and Preeclampsia groups. Symbols: - Control; - Preeclampsia; ${ }^{*} p \leq 0.05$. Abbreviations: GAD: Gestational Age at Delivery; NGT: normal glucose tolerance.

\subsection{Increased Maternal Urine $P_{i}$ Levels are Associated with Preeclampsia}

Decreased levels of $P_{i}$ have been described in the maternal urine of preeclampsia patients [32]. We quantified $\mathrm{P}_{\mathrm{i}}$ excretion in maternal urine from normotensive and preeclampsia groups. The average $\mathrm{P}_{\mathrm{i}}$ maternal urine level was higher in the preeclampsia group $(8.50 \pm 2.74 \mathrm{vs} .11 .52 \pm 2.90 \mathrm{mmol} / \mathrm{L}$; $p=0.4653)$, but this difference was not statistically significant (Figure 2A). Ectopic vascular calcification has been previously associated with preeclampsia [22,33]. von Kossa staining was used to detect calcified lesions on placental tissue slides of the preeclampsia group studied (Figure 2B-E). The average $\%$ Area Calcified was higher in the preeclampsia group $(0.0028 \pm 0.0014$ vs. $0.0048 \pm 0.0034 ; p=0.6117)$, but this difference was not statistically significant (Figure 2B). The distribution of the crystal deposits (black deposits) suggested a formation of calcium-phosphate deposits in chorionic villi (Figure 2D-E).

\subsection{Maternal Urine $P_{i}$ Levels Increase during Gestational Age}

Maternal urine $P_{i}$ levels were determined to assess $P_{i}$ variations over the course of human gestation. We observed that $P_{i}$ excretion increased between weeks 28-34 during third trimester of pregnancy in all cohorts (Figure 3A), and in both control and preeclampsia groups (Figure 3B). 
A.

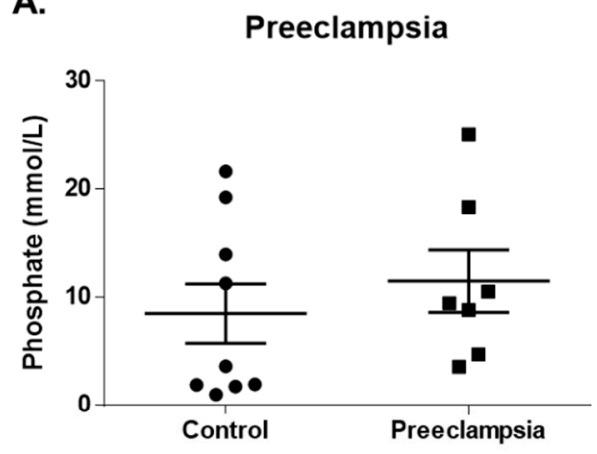

C.

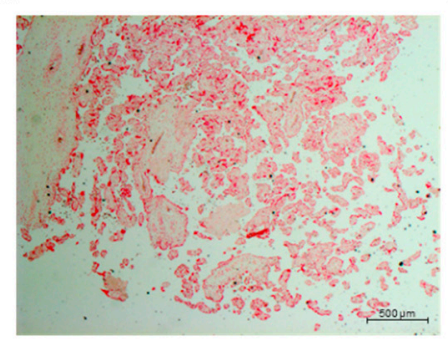

B.

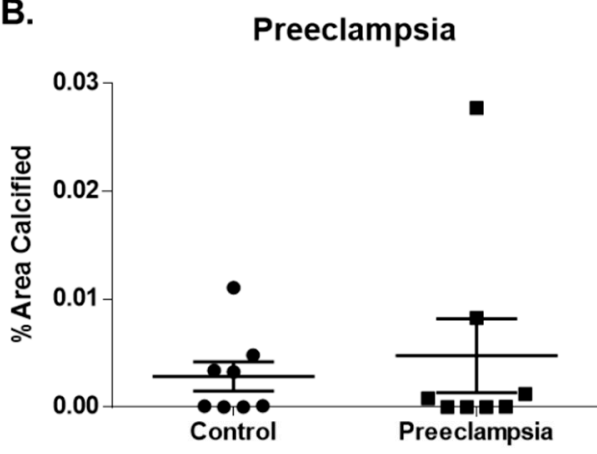

E.
D.

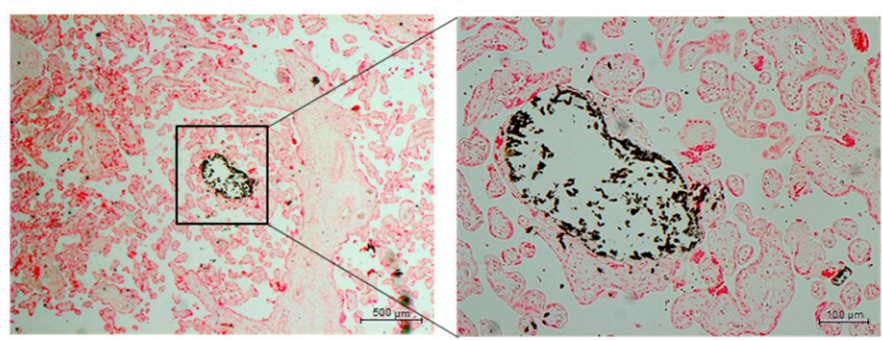

Figure 2. Maternal urine inorganic phosphate $\left(\mathrm{P}_{\mathrm{i}}\right)$ levels association with preeclampsia and placental calcification. Phosphate levels were determined for maternal urine (control, $n=9$; preeclampsia, $n=7$ ), and we observed a trend of increased phosphate levels with preeclampsia (A). urine (control, $n=9$; preeclampsia, $n=7$ ), and we observed a trend of increased phosphate levels with preeclampsia (A). Placental calcification (\% Area Calcified) was determined for placental tissue sections (control, $n=8$; preeclampsia, $n=8)$, and we observed a trend of increased placental calcification with preeclampsia (B). Images of von Kossa staining of a placental tissue section of preeclampsia donor identify negative (C) and positive regions $(\mathbf{D}, \mathbf{E})$ (black deposits; $\mathbf{C}$ and $\mathbf{D}$ magnification $\times 2.5$, E magnification $\times 10$ ). Box in (D) correspond to region imaged in (E). The distribution of the crystal deposits suggested a formation of calcium-phosphate mineral deposition at chorionic villi. Symbols: • Control; • Preeclampsia; $p \leq 0.05$.

A. Gestational Age at Delivery (GAD)

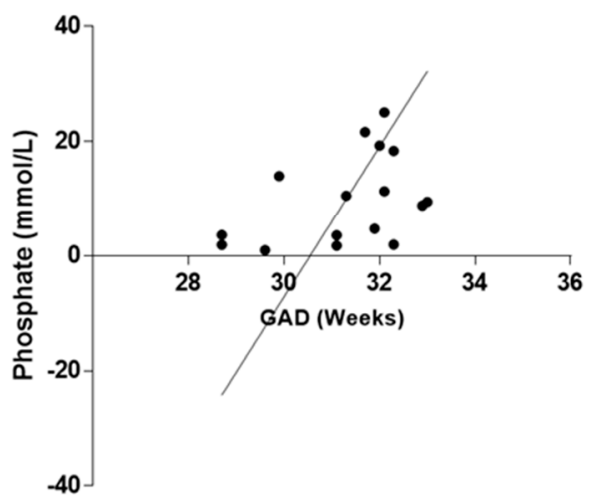

B. Gestational Age at Delivery (GAD)

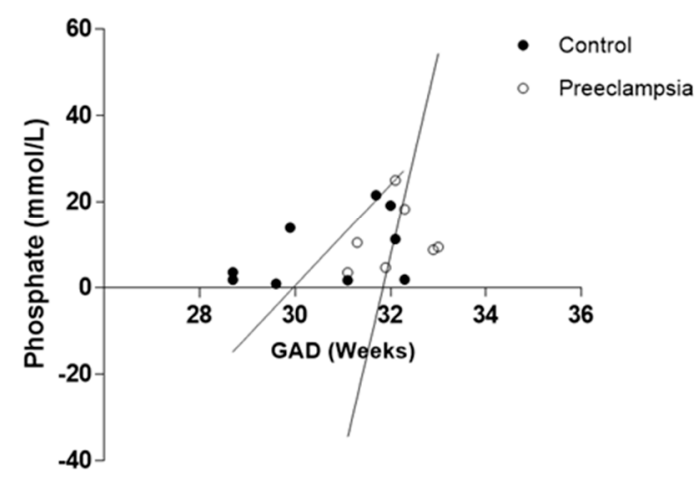

Figure 3. Maternal urine inorganic phosphate $\left(\mathrm{P}_{\mathrm{i}}\right)$ levels association with gestational age at delivery (GAD). Phosphate levels were determined for maternal urine (control, $n=9$; preeclampsia, $n=7$ ). We observed that phosphate levels increase with time during third trimester of pregnancy, in all cohort (A) and in both Control and Preeclampsia groups (B). Abbreviations: GAD: Gestational Age at Delivery. 


\subsection{Maternal Urine $P_{i}$ Levels Altered with Number of Pregnancies and with Diabetes and Preeclampsia}

We observed that $P_{i}$ levels decreased significantly on maternal urine with increased number of pregnancies ( $14.92 \pm 2.57$ vs. $4.72 \pm 1.59 \mathrm{mmol} / \mathrm{L} ; p=0.0045$; Figure $4 \mathrm{~A})$. This trend of decreased $\mathrm{P}_{\mathrm{i}}$ excretion in a second pregnancy for both normotensive and preeclampsia groups (Figure $4 \mathrm{~B}$ ), points to a putative decrease in bioavailability of phosphate with a second pregnancy. Furthermore, we observe a trend of increased average $\%$ Area Calcified in second pregnancies for both normotensive and preeclampsia groups ( $0.0007 \pm 0.0004$ vs. $0.0069 \pm 0.0033 ; p=0.0805$; Figure $4 \mathrm{C})$. Association of maternal urinary $\mathrm{P}_{\mathrm{i}}$ levels with preexisting diabetes mellitus $(100 \% \pm 35 \%$ vs. $141 \% \pm 34 \% \mathrm{mmol} / \mathrm{L} ; p=0.4180$; Figure $4 \mathrm{D})$ and preeclampsia (Figure $4 \mathrm{E}$ ) was evaluated, and indicated that diabetes dysregulates Pi excretion during pregnancy, and this is exacerbated with superimposed preeclampsia. In contrast, a modest trend of decreased average \% Area Calcified was observed with preexisting diabetes for both normotensive and preeclampsia groups $(0.0051 \pm 0.0033$ vs. $0.0025 \pm 0.0016 ; p=0.5005$; Figure $4 \mathrm{~F})$.

A.

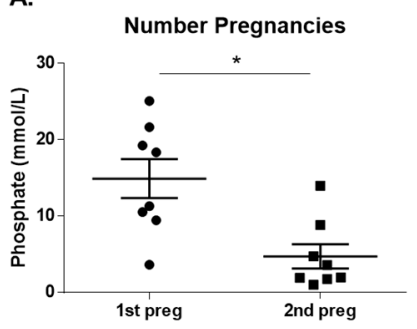

D.

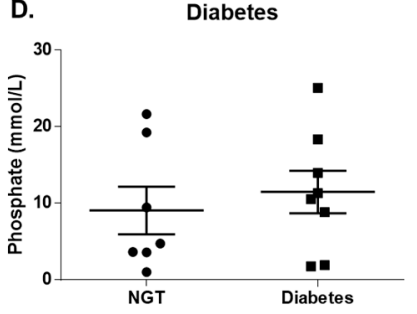

B.

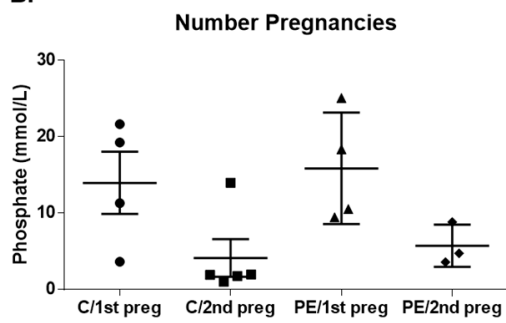

E.

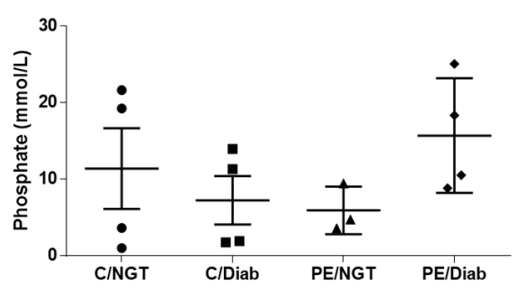

c.

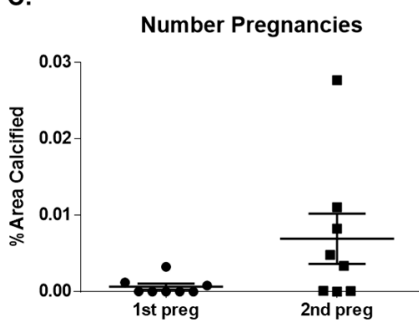

F.

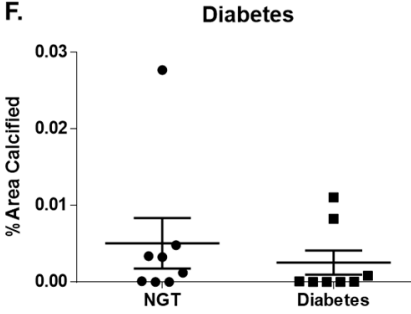

Figure 4. Maternal urine inorganic phosphate $\left(\mathrm{P}_{\mathrm{i}}\right)$ levels and placental calcification association with preexisting pregnancies, diabetes and preeclampsia. Phosphate levels were determined for maternal urine (control, $n=9$; preeclampsia, $n=7$ ). We observed that phosphate levels decrease with preexisting pregnancies in all cohorts (A). We observed a trend of reduced phosphate levels with preexisting pregnancies in both the Control and Preeclampsia groups (B). We observed a trend of increased phosphate levels with preexistence of diabetes in all cohorts (D) and Preeclampsia groups (E). Placental calcification (\% Area Calcified) was determined for placental tissue sections (control, $n=8$; preeclampsia, $n=8$ ), and we observed a trend of increased placental calcification with preexistence of previous pregnancies in all cohorts $(\mathbf{C})$ and decreased with preexistence of diabetes $(\mathbf{F})$. Symbols: ${ }^{*} p \leq 0.05$. Abbreviations: diab: diabetes; NGT: normal glucose tolerance; PE: preeclampsia; preg: pregnancy.

\subsection{Amniotic Fluid $P_{i}$ Levels Decrease during Gestational Age}

Amniotic fluid Pi levels were determined to assess $P_{i}$ variations over the course of human gestation. The gestational age at sample collection (GASC), between 17 and 35 weeks of pregnancy, overlaps the gestational age at delivery (GAD) 25 and 39 weeks (Figure 5A), which includes both second and third trimester of pregnancy. We observed that $P_{i}$ levels decrease with time during pregnancy (Figure 5C-D), in accordance with a previous study ran between 16-26 weeks [34]. Lastly, we tested whether $P_{i}$ was an indicator of preterm birth and observed an association between low second trimester phosphate amniotic fluid levels and preterm birth, supporting that $P_{i}$ should be examined more closely and in a larger population (Figure 5D). 

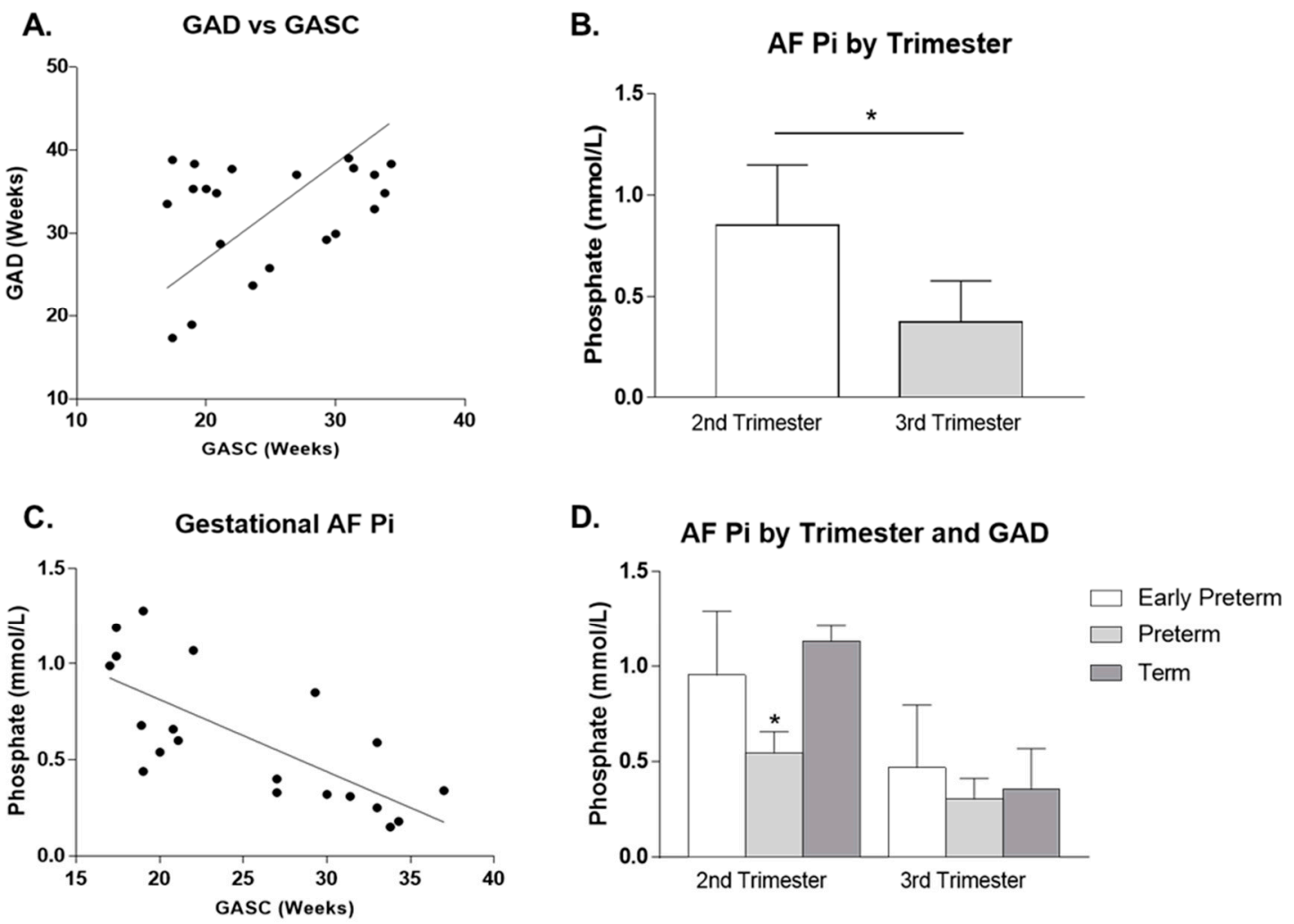

Figure 5. Amniotic fluid (AF) inorganic phosphate $\left(P_{i}\right)$ as an indicator of gestational age. Phosphate levels were determined with amniotic fluid collected between 17 and 35 weeks of pregnancy and we tested whether phosphate was an indicator for preterm birth (A). We observed that phosphate levels decrease with time during pregnancy $(\mathbf{B}, \mathbf{C})$ and an association between low second trimester levels and preterm birth (D). Symbols: ${ }^{*} p \leq 0.05$. Abbreviations: AF: amniotic fluid; GAD: gestational age at delivery; GASC: gestational age at sample collection; Pi: inorganic phosphate.

\section{Discussion}

Phosphorus is an essential micronutrient involved in a number of required biological processes. The purpose of this study was to characterize phosphate level dynamics over the course of gestation in maternal and fetal biological fluids. Hypophosphaturia is an important feature of severe preeclampsia that may be indirectly related to altered renal function [32]. The correlation with gestational age at delivery (GAD), pregnancy number, preterm birth, preeclampsia, diabetes mellitus, and placental calcification was evaluated. Potential confounding factors include maternal age at delivery and body mass index (BMI) - information which we do not have access to. Furthermore, the average GAD is higher for the preeclampsia group compared to the normotensive group, whilst no difference was observed regarding preexisting pregnancies and diabetes mellitus.

Maternal phosphate excretion increases during pregnancy, with maximum phosphate urine levels observed during the third trimester [35]. Similar to these findings, our study shows that maternal urine $\mathrm{P}_{\mathrm{i}}$ levels increased linearly between weeks 28-34 during the third trimester of pregnancy in all cohorts, including normotensive and preeclampsia groups. This supports that during pregnancy, decreased vascular resistance may induce adaptions, sustained by nitric oxide production, which results in the expansion of plasma volume by stimulating renal sodium and water retention and contributes to higher glomerular filtration rate (GFR) [36]. Renal excretion of both calcium and phosphate is decreased in preeclamptic women compared to normotensive women [32,37-39], as a possible result of a compensatory mechanism of decreased renal filtration rate and increased tubular reabsorption of calcium and phosphate in toxemia [32,39]. However, we observed a tendency of increased maternal urinary phosphate excretion in the preeclampsia group. The GAD in the preeclampsia is modestly 
higher in the preeclampsia group, which may contribute to this difference. Ectopic vascular calcification has also been previously associated with preeclampsia [22,33]. Indeed, we were able to detect calcified lesions on placental chorionic villi tissue slides of the preeclampsia group. We observed a trend of increased placental calcification on the preeclampsia group studied; however, by this method, there was no significant association in this cohort.

Phosphate metabolism is regulated by bone-derived FGF-23 and PTH, which influence the renal production and circulating concentrations of the active metabolite of VD, 1,25-hydroxyvitamin $\mathrm{D}[1,25(\mathrm{OH}) \mathrm{D}]$, which affects bone metabolism, intestinal absorption of calcium and phosphorus, and hypertension and vascular calcification [40]. Elevated serum phosphate has an inhibitory effect on the renal activation of 25-hydroxyvitamin $\mathrm{D}$ [25(OH)D] and 1,25-hydroxyvitamin D [1,25(OH)D], and lower concentrations of 1,25(OH)D have been associated with adverse cardiovascular outcomes [40]. During pregnancy, maternal serum levels of 1,25(OH)D increase up to twofold starting at 10-12 weeks of gestation and reaching a maximum in the third trimester [41,42]. As reviewed elsewhere [42], preeclamptic women are described to present lower circulating 25(OH)D3 levels than normotensive pregnant women, and VD supplementation showed promise for ameliorating the risk of PE. Contrary to the expected, we report an increase in maternal phosphaturia associated with preexisting diabetes mellitus alone. We also found that maternal urine $P_{\mathrm{i}}$ levels are higher in association with preexisting diabetes and preeclampsia compared to diabetes and normotensive participants. Moreover, placental calcification was shown to decrease with preexisting diabetes. Dietary intake may influence these differences, as Mancini FR et al. [43] reported a linear association between increasing dietary phosphorus intake, and the risk for type 2 diabetes in women.

To the best of our knowledge, the present study is the first to demonstrate an association between the number of pregnancies and maternal urine phosphate levels. Indeed, we observed that maternal urine $P_{i}$ levels decreased with a second pregnancy, which was consistent for both normotensive and preeclampsia groups, pointing to a putative decrease in the bioavailability of phosphate with a second pregnancy. However, mothers with preexisting pregnancies may present higher maternal age at delivery. It is well accepted that advanced maternal age is a risk factor for perinatal and neonatal outcomes, gestational diabetes mellitus, gestational hypertension, preeclampsia, small for gestational age infants, spontaneous late preterm delivery, and cesarean section [44]. Furthermore, we observed a trend of increased placental calcification with the number of pregnancies; however, there was no significant association in this cohort.

Lastly, we tested whether phosphate in amniotic fluid was an indicator of preterm birth and its variation over the course of gestation. We observed that amniotic fluid phosphate levels decreased with gestation while low second trimester levels were associated with preterm birth, which suggested that amniotic fluid may be useful as a marker of gestational age. These observations are in conformity with results previously reported $[34,45,46]$, that demonstrate that, during pregnancy, concentrations of phosphate [34,45,46] and calcium [45] decreased, and levels of uric acid [34,45] and creatinine [45,46] increased. This is consistent with the increasing fetal glomerular filtration rate and progressive maturation of tubular function, thus more micronutrients are resorbed at fetal tubules and, consequently, less will be excreted to the amniotic fluid $[34,45,46]$.

During pregnancy, maternal bone mineral density (BMD) and bone resorption markers are modestly increased $[21,22,42,47]$. With increased number of pregnancies, we hypothesize that the BMD and phosphorus and calcium bioavailability is reduced. However, the information regarding maternal pre-pregnancy BMI as an indicator of maternal nutritional status was not available. Potential limitations to this study should be considered and addressed through future studies that build on these findings to evaluate candidate modifiers, such as maternal age at delivery, maternal body mass index (BMI), biological levels of calcium, VD, PTH, genetics and lifestyle. Future work will evaluate the relationship between phosphate dysregulation in preeclampsia, diabetes, maternal age, and number of pregnancies through the analysis of the tissue-specific and cell-specific nature of calcified lesions; expression of placental phosphate transporter expression levels (Slc20a1 and Slc20a2) and osteochondrogenic factors; 
maternal urinary calcium and phosphate excretion; and maternal age. In conclusion, phosphate levels provide clinical information regarding temporal fluctuation of maternal-fetal phosphate homeostasis in pregnancy-related complications, supporting that phosphate should be examined more closely and in larger populations.

Author Contributions: A.C.-B. performed most of the experiments and data analysis, and formal A.C.-B. contributor roles include data curation, formal analysis, investigation, validation, visualization, and writing (original draft, review, and editing). M.P.R. and L.M.P. contributor roles include data curation, project administration, resources, and writing (review \& editing). M.C.W. contributor roles include conceptualization, data curation, formal analysis, funding acquisition, investigation, project administration, supervision, and writing (original draft, review, and editing). All authors have read and agreed to the published version of the manuscript.

Funding: This work was funded by National Institutes of Health K99/R00HD090198 (M. Wallingford); American Heart Association 19CDA34660038 (M. Wallingford).

Conflicts of Interest: The authors have no financial relationships, patents, or copyrights to declare. No payment or services from a third party were received for any aspect of the submitted work.

\section{Abbreviations}

1:25(OH)D
BMD
CKD
FGF23
GAD
GASC
GFR
NGT
PE
$P_{\mathrm{i}}$
PO
PTH
PTHrP
Slc20a1(PiT-1)/Slc20a2 (PiT-2)
VD

\author{
1,25-hydroxyvitamin D \\ Bone mineralization disorders \\ Chronic kidney disease \\ Fibroblast growth factor 23 \\ Gestation age of delivery \\ Gestation age of sample collection \\ Glomerular filtration rate \\ Normal glucose tolerance \\ Preeclampsia \\ Inorganic phosphate \\ Phosphoric acid \\ Parathyroid hormone \\ PTH-related protein \\ Sodium-dependent phosphate transporters \\ Vitamin D
}

\section{References}

1. Forster, I.; Hernando, N.; Sorribas, V.; Werner, A. Phosphate transporters in renal, gastrointestinal, and other tissues. Adv. Chronic Kidney Dis. 2011, 18, 63-76. [CrossRef] [PubMed]

2. Virkki, L.V.; Biber, J.; Murer, H.; Forster, I.C. Phosphate transporters: A tale of two solute carrier families. Am. J. Physiol. Renal Physiol. 2007, 293, F643-F654. [CrossRef] [PubMed]

3. Yang, H.; Kim, T.H.; Lee, G.S.; Hong, E.J.; Jeung, E.B. Comparing the expression patterns of placental magnesium/phosphorus-transporting channels between healthy and preeclamptic pregnancies. Mol. Reprod. Dev. 2014, 81, 851-860. [CrossRef] [PubMed]

4. DiGirolamo, D.J.; Clemens, T.L.; Kousteni, S. The skeleton as an endocrine organ. Nat. Rev. Rheumatol. 2012, 8, 674-683. [CrossRef] [PubMed]

5. Ryan, B.A.; Kovacs, C.S. Calciotropic and phosphotropic hormones in fetal and neonatal bone development. Semin. Fetal. Neonatal. Med. 2020, 25, 101062. [CrossRef] [PubMed]

6. Marks, J. The role of SLC34A2 in intestinal phosphate absorption and phosphate homeostasis. Pflüg. Arch. Eur. J. Physiol. 2019, 471, 165-173. [CrossRef]

7. Marks, J.; Debnam, E.S.; Unwin, R.J. Phosphate homeostasis and the renal-gastrointestinal axis. Am. J. Physiol. Renal Physiol. 2010, 299, F285-F296. [CrossRef]

8. Marks, J.; Debnam, E.S.; Unwin, R.J. The role of the gastrointestinal tract in phosphate homeostasis in health and chronic kidney disease. Curr. Opin. Nephrol. Hypertens. 2013, 22, 481-487. [CrossRef]

9. Underwood, M.A.; Gilbert, W.M.; Sherman, M.P. Amniotic fluid: Not just fetal urine anymore. J. Perinatol. 2005, 25, 341-348. [CrossRef] 
10. Chesley, L.C.; Annitto, J.E.; Cosgrove, R.A. The remote prognosis of eclamptic women. Sixth periodic report. Am J Obstet. Gynecol. 1976, 124, 446-459. [CrossRef]

11. Smith, G.C.; Pell, J.P.; Walsh, D. Pregnancy complications and maternal risk of ischaemic heart disease: A retrospective cohort study of 129,290 births. Lancet 2001, 357, 2002-2006. [CrossRef]

12. Diniz, A.L.D.; Paes, M.; Diniz, A.D. Analyzing Preeclampsia as the Tip of the Iceberg Represented by Women with Long-Term Cardiovascular Disease, Atherosclerosis, and Inflammation. Curr. Atheroscler. Rep. 2020, 22, 13. [CrossRef]

13. Benschop, L.; Schelling, S.J.; Duvekot, J.J.; van Lennep, J.E.R. Cardiovascular health and vascular age after severe preeclampsia: A cohort study. Atherosclerosis 2020, 292, 136-142. [CrossRef] [PubMed]

14. Bokslag, A.; Teunissen, P.W.; Franssen, C.; van Kesteren, F.; Kamp, O.; Ganzevoort, W.; Paulus, W.J.; de Groot, C.J. Effect of early-onset preeclampsia on cardiovascular risk in the fifth decade of life. Am. J. Obstet. Gynecol. 2017, 216, 523 e1-523 e7. [CrossRef] [PubMed]

15. Ying, W.; Catov, J.M.; Ouyang, P. Hypertensive Disorders of Pregnancy and Future Maternal Cardiovascular Risk. J. Am. Heart Assoc. 2018, 7, e009382. [CrossRef]

16. ACOG Practice Bulletin No. 202: Gestational Hypertension and Preeclampsia. Obstet. Gynecol. 2019, 133, e1-e25.

17. Young, B.C.; Levine, R.J.; Karumanchi, S.A. Pathogenesis of preeclampsia. Annu. Rev. Pathol. 2010, 5, $173-192$. [CrossRef]

18. Ray, J.G.; Vermeulen, M.J.; Schull, M.J.; Redelmeier, D.A. Cardiovascular health after maternal placental syndromes (CHAMPS): Population-based retrospective cohort study. Lancet 2005, 366, 1797-1803. [CrossRef]

19. Ulrich, U.; Miller, P.B.; Eyre, D.R.; Chesnut, C., III; Schlebusch, H.; Soules, M.R. Bone remodeling and bone mineral density during pregnancy. Arch. Gynecol. Obstet. 2003, 268, 309-316. [CrossRef]

20. Anim-Nyame, N.; Sooranna, S.R.; Jones, J.; Alaghband-Zadeh, J.; Steer, P.J.; Johnson, M.R. A longitudinal study of biochemical markers of bone turnover during normal pregnancy and pregnancies complicated by pre-eclampsia. BJOG Int. J. Obs. Gynaecol. 2002, 109, 708-713. [CrossRef]

21. To, W.W.; Wong, M.W. Bone mineral density changes in pregnancies with gestational hypertension: A longitudinal study using quantitative ultrasound measurements. Arch. Gynecol. Obstet. 2011, 284, 39-44. [CrossRef] [PubMed]

22. Beckman, J.P.; Camp, J.J.; Lahr, B.D.; Bailey, K.R.; Kearns, A.E.; Garovic, V.D.; Jayachandran, M.; Miller, V.M.; Holmes, D.R., III. Pregnancy history, coronary artery calcification and bone mineral density in menopausal women. Climacteric 2018, 21, 53-59. [CrossRef] [PubMed]

23. Miettola, S.; Hovi, P.; Andersson, S.; Strang-Karlsson, S.; Pouta, A.; Laivuori, H.; Järvenpää, A.L.; Eriksson, J.G.; Mäkitie, O.; Kajantie, E. Maternal preeclampsia and bone mineral density of the adult offspring. Am. J. Obstet. Gynecol. 2013, 209, 443 e1-443 e10. [CrossRef]

24. Miettola, S.; Hovi, P.; Andersson, S.; Strang-Karlsson, S.; Pouta, A.; Laivuori, H.; Järvenpää, A.L.; Eriksson, J.G.; Mäkitie, O.; Kajantie, E. PP083. Maternal pre-eclampsia and bone mineral density of the adult offspring. Pregnancy Hypertens 2013, 3, 98. [CrossRef]

25. El-Abbadi, M.M.; Pai, A.S.; Leaf, E.M.; Yang, H.Y.; Bartley, B.A.; Quan, K.K.; Ingalls, C.M.; Liao, H.W.; Giachelli, C.M. Phosphate feeding induces arterial medial calcification in uremic mice: Role of serum phosphorus, fibroblast growth factor-23, and osteopontin. Kidney Int. 2009, 75, 1297-1307. [CrossRef] [PubMed]

26. Shanahan, C.M.; Crouthamel, M.H.; Kapustin, A.; Giachelli, C.M. Arterial calcification in chronic kidney disease: Key roles for calcium and phosphate. Circ. Res. 2011, 109, 697-711. [CrossRef] [PubMed]

27. Lau, W.L.; Festing, M.H.; Giachelli, C.M. Phosphate and vascular calcification: Emerging role of the sodium-dependent phosphate co-transporter PiT-1. Thromb. Haemost. 2010, 104, 464-470. [CrossRef] [PubMed]

28. Scantlebury, D.C.; Hayes, S.N.; Garovic, V.D. Pre-eclampsia and maternal placental syndromes: An indicator or cause of long-term cardiovascular disease? Heart 2012, 98, 1109-1111. [CrossRef]

29. Mastrolia, S.A.; Weintraub, A.Y.; Sciaky-Tamir, Y.; Tirosh, D.; Loverro, G. Hershkovitz R.Placental calcifications: A clue for the identification of high-risk fetuses in the low-risk pregnant population? J. Matern. Fetal Neonatal Med. 2016, 29, 921-927. [CrossRef]

30. Mirza, F.G.; Ghulmiyyah, L.M.; Tamim, H.; Makki, M.; Jeha, D.; Nassar, A. To ignore or not to ignore placental calcifications on prenatal ultrasound: A systematic review and meta-analysis. J. Matern. Fetal Neonatal Med. 2018, 31, 797-804. [CrossRef]

31. Speer, M.Y.; Yang, H.Y.; Brabb, T.; Leaf, E.; Look, A.; Lin, W.L.; Frutkin, A.; Dichek, D.; Giachelli, C.M. Smooth muscle cells give rise to osteochondrogenic precursors and chondrocytes in calcifying arteries. Circ. Res. 2009, 104, 733-741. [CrossRef] [PubMed] 
32. Vural, P.; Akgul, C.; Canbaz, M. Calcium and Phosphate Excretion in Preeclampsia. Turk. J. Med. Sci. 2000, 30, 39-42.

33. Miller, V.M.; Garovic, V.D.; Bailey, K.R.; Lahr, B.D.; Mielke, M.M.; White, W.M. Jayachandran M Pregnancy history and blood-borne microvesicles in middle aged women with and without coronary artery calcification. Atherosclerosis 2016, 253, 150-155. [CrossRef] [PubMed]

34. Fotiou, M.; Michaelidou, A.M.; Athanasiadis, A.P.; Menexes, G.; Symeonidou, M.; Koulourida, V.; Ganidou, M.; Theodoridis, T.D.; Tarlatzis, B.C. Second trimester amniotic fluid glucose, uric acid, phosphate, potassium, and sodium concentrations in relation to maternal pre-pregnancy BMI and birth weight centiles. J. Matern. Fetal Neonatal Med. 2015, 28, 910-915. [CrossRef]

35. Mozdzien, G.; Schinninger, M.; Zazgornik, J. [Kidney function and electrolyte metabolism in healthy pregnant women]. Wien. Med. Wochenschr. 1995, 145, 12-17. [PubMed]

36. Lopes van Balen, V.A.; van Gansewinkel, T.A.; de Haas, S.; Spaan, J.J.; Ghossein-Doha, C.; van Kuijk, S.M.; van Drongelen, J.; Cornelis, T.; Spaanderman, M.E. Maternal kidney function during pregnancy: Systematic review and meta-analysis. Ultrasound Obstet. Gynecol. 2019, 54, 297-307. [CrossRef]

37. Segovia, B.L.; Vega, I.T.; Villarreal, E.C.; Licona, N.A. [Hypocalciuria during pregnancy as a risk factor of preeclampsia]. Ginecol. Obstet. Mex. 2004, 72, 570-574.

38. Taufield, P.A.; Ales, K.L.; Resnick, L.M.; Druzin, M.L.; Gertner, J.M.; Laragh, J.H. Hypocalciuria in preeclampsia. N. Engl. J. Med. 1987, 316, 715-718. [CrossRef]

39. Yoshida, A.; Morozumi, K.; Suganuma, T.; Sato, K.; Aoki, J.; Oikawa, T.; Fujinami, T. [Urinary calcium excretion in toxemia of pregnancy]. Nihon Jinzo Gakkai Shi 1989, 31, 327-334.

40. Calvo, M.S.; Uribarri, J. Public health impact of dietary phosphorus excess on bone and cardiovascular health in the general population. Am. J. Clin. Nutr. 2013, 98, 6-15. [CrossRef]

41. Brannon, P.M.; Picciano, M.F. Vitamin D in pregnancy and lactation in humans. Annu. Rev. Nutr. 2011, 31, 89-115. [CrossRef] [PubMed]

42. Triunfo, S.; Lanzone, A. Potential impact of maternal vitamin D status on obstetric well-being. J. Endocrinol. Investig. 2016, 39, 37-44. [CrossRef] [PubMed]

43. Mancini, F.R.; Affret, A.; Dow, C.; Balkau, B.; Clavel-Chapelon, F.; Bonnet, F.; Boutron-Ruault, M.C.; Fagherazzi, G. High dietary phosphorus intake is associated with an increased risk of type 2 diabetes in the large prospective E3N cohort study. Clin. Nutr. 2018, 37, 1625-1630. [CrossRef] [PubMed]

44. Kahveci, B.; Melekoglu, R.; Evruke, I.C.; Cetin, C. The effect of advanced maternal age on perinatal outcomes in nulliparous singleton pregnancies. BMC Pregnancy Childb. 2018, 18, 343. [CrossRef]

45. Oliveira, F.R.; Barros, E.G.; Magalhaes, J.A. Biochemical profile of amniotic fluid for the assessment of fetal and renal development. Braz. J. Med. Biol. Res. 2002, 35, 215-222. [CrossRef]

46. Nicolini, U.; Fisk, N.M.; Rodeck, C.H.; Beacham, J. Fetal urine biochemistry: An index of renal maturation and dysfunction. Br. J. Obstet. Gynaecol. 1992, 99, 46-50. [CrossRef]

47. Kovacs, C.S.; Vitamin, D. In pregnancy and lactation: Maternal, fetal, and neonatal outcomes from human and animal studies. Am. J. Clin. Nutr. 2008, 88, 520S-528S. [CrossRef]

(C) 2020 by the authors. Licensee MDPI, Basel, Switzerland. This article is an open access article distributed under the terms and conditions of the Creative Commons Attribution (CC BY) license (http://creativecommons.org/licenses/by/4.0/). 